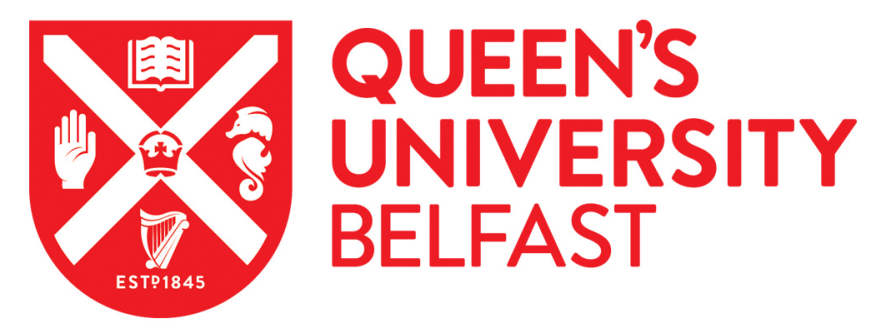

\title{
Numerical simulation of a patent technology for sealing of deep-sea oil wells using nonlinear finite element method
}

Abdelal, G. F., Robotham, A., \& Carragher, P. (2015). Numerical simulation of a patent technology for sealing of deep-sea oil wells using nonlinear finite element method. Journal of Petroleum Science and Engineering, 133, 192-200. https://doi.org/10.1016/j.petrol.2015.05.010

Published in:

Journal of Petroleum Science and Engineering

Document Version:

Peer reviewed version

Queen's University Belfast - Research Portal:

Link to publication record in Queen's University Belfast Research Portal

Publisher rights

(C) 2015, Elsevier. Licensed under the Creative Commons Attribution -NonCommercial-NoDerivs License

(https://creativecommons.org/licenses/by-nc-nd/4.0/), which permits distribution and reproduction for non-commercial purposes, provided the author and source are cited

\section{General rights}

Copyright for the publications made accessible via the Queen's University Belfast Research Portal is retained by the author(s) and / or other copyright owners and it is a condition of accessing these publications that users recognise and abide by the legal requirements associated with these rights.

Take down policy

The Research Portal is Queen's institutional repository that provides access to Queen's research output. Every effort has been made to ensure that content in the Research Portal does not infringe any person's rights, or applicable UK laws. If you discover content in the Research Portal that you believe breaches copyright or violates any law, please contact openaccess@qub.ac.uk. 


\title{
Numerical Simulation of a Patent Technology for Sealing
}

\section{of Deep-sea Oil Wells Using Nonlinear Finite Element}

\section{Method}

\author{
Gasser F. Abdelal 1, Antony Robotham 2 , Paul Carragher ${ }^{3}$ \\ 1 School of Mechanical and Aerospace Engineering, Queens's University, Belfast, BT7 1NN, UK, \\ g.abdelal@qub.ac.uk, phone: +44 (0)28 9097 4123, Fax: +44 (0)28 90974148 \\ ${ }^{2}$ Senior Lecturer, School of Engineering, Auckland University of Technology, Auckland 1010, New Zealand \\ ${ }^{3}$ CEO at BiSN Technologies Ltd, Warrington WA7 1SS, UK
}

Abstract. For over 50 years bridge plugs and cement have been used for well abandonment, work over, and are still the material of choice. However the failures of cement abandonments using bridge plugs has been reported on many occasions, some of which have resulted in fatal consequences. A new patented product is designed to address the shortcomings associated with using bridge plugs and cement. The new developed tools use an alloy based on bismuth that is melted in situ using Thermite reaction. The tool uses the expansion properties of bismuth to seal the well. Testing the new technology in real field under more than $2 \mathrm{~km}$ deep sea water can be expensive. Virtual simulation of the new device under simulated thermal and mechanical environment can be achieved using nonlinear finite element method to validate the product and reduce cost. Experimental testing in the lab is performed to measure heat generated due to thermite reaction. Then, a sequential thermal mechanical explicit/implicit finite element solver is used to simulate the device under both testing lab and deep water conditions.

\section{Keywords}

Finite element; Thermal; Oil well; Melting; Seal; Thermite.

\section{Introduction}

In this paper, a research program was implemented to assist BiSN-UK in developing a new technology that may help to eliminate the environmental pollution in the world due to abandoned 
oil wells. Government reports have warned for decades that abandoned wells can provide pathways for oil, gas or brine-laden water to contaminate groundwater supplies or to travel up to the surface. Abandoned wells have polluted the drinking water source for Fort Knox, Ky, USA, and leaked oil into water wells in Ohio and Michigan. Similar problems have occurred in Texas, New York, Colorado and other states where drilling has occurred. In 2008, gas from an abandoned well leaked into a septic system in Pennsylvania and exploded when someone tried to light a candle in a bathroom, killing the person, according to a 2009 draft report by the state's Department of Environmental Protection.

Bridge plugs are a mechanical plug that is used to provide a solid seal within a wellbore for plugging. Some bridge plugs are designed to be easily drillable in case the well is desired to be reentered later. Bridge plugs are typically made of cast iron with duel slips with a sealing element between the slips.

The plug is designed to be set in a wellbore and then have cement set on top to provide a complete seal of the reservoir below. Oil wells with moderate to high-pressure gas use bridge plugs to seal the wellbore before cementing to reduce the chances of the pressurized water or gas to contaminate the cement [2]. A cement retainer is a mechanical plug that can be set above a zone to be cemented. This type of plug is especially useful when plugging higher pressured zones that need to be squeeze cemented prior to plugging. Cement retainers are usually built from drillable material so will yield to later re-entry of the reservoir as needed. The cement retainer is set in the well in a method similar to that used for a bridge plug. Once the tool is set in the well, cement can be pumped through the plug to squeeze cement through the perforations or open-hole area below the retainer [2]. Bridge plugs are manufactured from a number of materials that each has their own applicable benefits and disadvantages. For instance, bridge plugs made out of composite materials are often used in high-pressure applications because they are able to withstand pressures of $18,000-20,000$ psi (124-137 MPa). On the other hand, their permanent use tends to lend itself to slippage over 
time due to the lack of bonding between the composite materials and the materials inside the wellbore. Bridge plugs fabricated out of cast iron or another metal may be perfect for long-term or even permanent applications, however, they don't adhere very well in high-pressure situations.

BiSN-UK is developing a new technology for sealing of oil wells under deep sea water. The new patent geometry is shown in Fig.2. The plug consists from three main components; ignition system, alloy jacket (bismuth alloy), skirt, and inner tube. The inner tube is filled with a thermite alloy mix, which is part of the ignition system. The plug is inserted in the center of the oil well. Then, igniting the thermite alloy mix generates enough heat to melt the alloy jacket. The melted alloy jacket fill the gap between the plug and the well's wall filling even any corroded surfaces or surface cracks. The melted alloy cools down and solidifies to keep the bridge plug in place under the pressure difference between deep-sea water pressure and gas pressure build up from inside the well. Bismuth is one of the few elements that expand on solidification and it is one of the reasons bismuth is selected for this patent design. The BiSN bridge Plug has been developed to be run on a standard wireline with no need for a workover rig. This greatly reduces the rig time needed to complete abandonments (P\&A) or work overs. As well as providing a superior seal compared with bridge plugs, the costs are also significantly reduced due to the reduced rig time. Another advantage from using the BiSN bridge plug is the ability of repeating the sealing process after a number of years for assurance of sealing quality or its removal to use the oil well. The bismuth based alloy plug is also highly corrosion resistant and is not affected by Hydrogen Sulphide. The BiSN bridge plug offers a faster, superior and more cost effective solution to alternative products and bridge plugs on the market.

The device is projected for sealing of oil well under seawater at depth up to 2000 meters. An oil well may have a number of casings, which fit inside each other. Therefore, a well might start with an initial 20-inch diameter, drill a short distance, perhaps $200 \mathrm{ft}$, and then cement in a conductor casing and begin to drill a smaller diameter hole. Very common diameters for wells at the 
completion depth are 7 to 12 inches. Slimholes are any well with less than 4.5 inch. The device of 4.5 inch in diameter has been tested in the lab under atmospheric pressure environment but not at different mechanical/thermal conditions that exists at depth of 2000 meters. Numerical simulation using nonlinear finite element method is used to validate the device functionality under harsh deep sea level conditions. Numerical simulations aim at achieving two objectives. First objective is to increase BiSN confidence in their mechanical design by validating its function at early stage of the development cycle and reduce the project cost by minimizing the number of prerequisite real field device tests. Second objective is to generate a virtual model of the sealing procedure that can be used in design optimization of the device.

BiSN developed a testing device that is capable of simulating the sealing process of oil well of size 4.5-inch case under test lab conditions. The testing device is capable of providing temperature distribution on the plug as a function of time, and provides an estimation of the critical pressure difference at which the bridge-plug starts to shift (after solidification). The test results show that the bridge-plug shifts at 4000 psi pressure difference. For the bridge-plug to pass the certification committee, it needs to hold pressure difference of 4000 psi for 5 minutes. The Sealing process consists of 4 discrete operations; thermite ignition, heat wave is travelling along the bridge-plug causing the alloy-jacket to melt. The alloy-jacket as it melts it shifts down along the plug under gravity and water pressure. Then, the alloy jacket solidifies and expands to seal the oil well. Two critical parameters should be investigated; the maximum stresses in the oil-well case due to the expansion of the alloy jacket, and the pressure difference that will overcome the friction forces between the alloy jacket and the inner of the oil-well case and cause the Bridge-Plug to shift.

\section{Material Models}

The BiSN patent for sealing of oil well under sea water consists from steel case that host the inner tube for Thermite reaction and outer tube for Alloy Jacket support, skirt made from steel to hold the alloy jacket as it melts and shifts, and bismuth alloy jacket. The material type used for the steel is an 
undisclosed SA-XXX alloy, similar in composition to SA-335, while the material type used for the alloy jacket is undisclosed Sn-XX Bi alloy, similar to Sn-57Bi-1AG. The oil well material is modelled with similar type of steel. Thermal material properties are required to perform heat transfer analysis to simulate heat conduction between thermite and alloy jacket through inner and out tubes, phase transformation heat (melting), and conduction of the alloy jacket to the surrounding environment and the oil well walls. Mechanical material properties are required to model melting (softening), shifting of the alloy jacket along the devise case to seal the oil well, and expansion of the jacket alloy as it solidifies. The Sn-XX Bi's thermal expansion property and its low melting temperature point $\left(138.0{ }^{\circ} \mathrm{C}\right)$ are the motives this alloy is used for the bridge-plug application. Thermal properties of the device materials are listed in Table 1.

Ramberg-Osgood [3] is used to model the temperature dependant plasticity of the Sn-XX Bi alloy jacket,

$$
\begin{aligned}
& \varepsilon_{t}^{e p}=\frac{\sigma_{t}}{E}+\varepsilon_{o}\left(\frac{\sigma_{t}}{D}\right)^{m} \\
& E=1.82 \mathrm{E} 2 \mathrm{e}^{(-6.59 E-3) \cdot T} \quad G P a \\
& D=(7.34 \mathrm{E} 2) \mathrm{e}^{(-8.58 E-3) \cdot T} \quad M P a \\
& m=68.7(T)^{-0.544} \\
& \varepsilon_{o}=5 E-4
\end{aligned}
$$

Where, $\varepsilon_{t}^{e p}$ is strain, $\sigma$ is stress, $\mathrm{E}$ is Young's modulus, $\mathrm{m}$ and $\varepsilon_{o}$ are material parameters, $\mathrm{D}$ is material yield stress, $\mathrm{T}$ is temperature in ${ }^{\circ} \mathrm{K}$.

Volume expansion of the bismuth alloy is modelled using UEXPAN - Abaqus user material subroutine. UEXPAN is used to define incremental thermal strains as functions of temperature, predefined field variables, and state variables, and is intended for models in which the thermal strains depend on temperature. Thermal expansion coefficient, $\alpha$, of the 
bismuth alloy is calculated based on material data sheet that is supplied from the material supplier and can be defined as,

$$
\begin{aligned}
& \text { Linear growth } \quad \Delta \mathrm{L}=\alpha . \mathrm{L} . \Delta \mathrm{T} \\
& \text { Volume expansion } \quad \Delta \mathrm{V}=3.0 \quad \alpha . \mathrm{V} . \Delta \mathrm{T} \\
& \alpha=1.5 E-5 \quad T \leq 124.0 \\
& \alpha=2.553 E-3 \quad 124.0<T<125.0 \\
& \alpha=1.667 E-4 \quad T \geq 125.0
\end{aligned}
$$

Where, $\mathrm{L}$ is linear dimension, $\mathrm{V}$ is volume, $\mathrm{T}$ is temperature, $\Delta \mathrm{T}$ is change is temperature, and $\alpha$ is thermal expansion coefficient.

\section{Experimental measurements of Thermite Heat Reaction}

The $\mathrm{Al}-\mathrm{Fe}_{2} \mathrm{O}_{3}$ system is famous by the exothermic reaction that it experiences when submitted to thermal and/or mechanical ignition [3]. According to the following stoichiometric reaction,

$$
8 \mathrm{Al}+3 \mathrm{Fe}_{2} \mathrm{O}_{3} \rightarrow 2 \mathrm{Fe}_{3} \mathrm{Al}+3 \mathrm{Al}_{2} \mathrm{O}_{3}
$$

The final phases, $\mathrm{Al}_{2} \mathrm{O}_{3}$ and $\mathrm{Fe}_{3} \mathrm{Al}$ intermetallic, are formed by a chemical reaction in which $\mathrm{Al}$ reduces the iron oxide. Fan et al. [4] used non-isothermal differential scanning calorimetry (DSC) and X-ray diffraction experiments to analyze the reaction kinetics of $\mathrm{Al}-\mathrm{Fe}_{2} \mathrm{O}_{3}$ system by a modelfree Starink method. In his study, activation energy was determined as $145 \mathrm{~kJ} / \mathrm{mol}$ for $8 \mathrm{Al}-3 \mathrm{Fe}_{2} \mathrm{O}_{3}$ thermite reaction, the value is comparable to the activation energy for diffusion of $\mathrm{Al}$ in $\mathrm{FeAl}_{2} \mathrm{O}_{4}$ and is less than the activation energy for diffusion of $\mathrm{Al}$ in $\mathrm{Fe}_{3} \mathrm{Al}$, suggesting that the diffusion of $\mathrm{Al}$ into $\mathrm{FeAl}_{2} \mathrm{O}_{4}$ controls the product of the thermite reaction. Fan et al.[4] used the following formula that simulate the standard kinetics of thermally solid-state reactions,

$$
\frac{d \alpha}{d t}=A \exp \left(-\frac{E_{a}}{R T}\right) f(\alpha)
$$

Where $\alpha$ is the extent of reaction, $t$ the time, $R$ is the universal constant, $T$ is the temperature, $f(\alpha)$ is the kinetic model function, and $A$ and $E_{a}$ are the apparent pre-exponential factor and apparent 
activation energy, respectively. Fan [4] used a new method for the derivation of activation energies is proposed by Starink [5]. It was shown [5] that this method is an order of magnitude more accurate than the Kissinger and Ozawa methods [6]. These methods all comply with the following equation,

$$
\ln \left(\frac{T_{p}}{\phi}\right)=A \frac{E_{a}}{R T_{p}}+\mathrm{S}
$$

Where, $T_{\mathrm{P}}$ is the peak temperature of the DSC curve, $\varphi$ is the heating rate, $S$, is a constant, and $A$ is a constant which depends on the choice of $S$. In the case of Kissinger's method $s=2$ and $A=1$, the Ozawa methods $S=0$ and $A=1.0518$, while the Starink methods $S=1.8$ and $A=1.007-(1.2 \mathrm{e}-5) \cdot E_{\mathrm{a}}$ $\left(E_{\mathrm{a}}\right.$ in $\mathrm{kJ} / \mathrm{mol}$ ). Starink applied the latter method, and determined $E_{\mathrm{a}}$ of the $8 \mathrm{Al}-3 \mathrm{Fe}_{2} \mathrm{O}_{3}$ thermite reaction to be $145 \mathrm{~kJ} / \mathrm{mol}$.

Thermite reaction heat is estimated using experimental technique instead of modelling the reaction numerically, as sand was added to the Thermite formula to reduce the amount of heat generated. The percentage of sand that was added and placed in specific space in the inner tube of the sealing device is undisclosed and cannot be discussed here. The experimental technique used to estimate heat reaction and its results are discussed in this section.

Only the device's inner tube is used during the measurements of the heat generated after the ignition of the Thermite mix. The Thermite mix is placed in the inner tube, which is inserted in a bucket of sand as shown in Fig.2. The bucket of sand is used for fixing of the inner tube and to contain the reactants of the Thermite ignition reaction. The Thermite is ignited using fire torch. Eight thermocouples are installed at equal distance and connected to a data acquisition system to record temperature as a function of time. Thermite reaction lasts for about 5 minutes. The recorded temperature data is used as an input for the heat transfer analysis using finite element method. The experimental measurements of the Thermite mix reaction is performed in lab at room temperature around $21^{\circ} \mathrm{C}$, while the deep sea water temperature conditions is around $60{ }^{\circ} \mathrm{C}$. Furthermore, there 
is heat convection to the surrounding air, instead of to the outer case of the sealing device. Thus the recorded data has to be corrected for the environmental temperature difference by shifting them by $39{ }^{\circ} \mathrm{C}$, while the heat convection to air is calculated and it will be applied as heat load on the inner surface of the outer case of the sealing device during the heat transfer analysis. Test results are shown in Fig. 3, where the peak temperature of the Thermite reaction is reached after 500 sec. The lowest peak temperature is at the top thermocouple, and the highest one is at the bottom thermocouple. The time difference between the second peak and highest peak temperatures is around $200 \mathrm{sec}$, which reflects the reaction wave speed. The top thermocouple is installed further from the top surface of the Thermite mix and that is the cause of its lower peak temperature and its time delay with respect to the peak temperature of the second thermocouple.

\section{Nonlinear finite element analysis}

Fig. 4 shows the finite element meshed model of the oil well sealing device using Abaqus 6.11. The 8-node linear brick element is used to mesh the model assembly. The inner tube and the outer tube are meshed with $10 \mathrm{~mm}$ elements size, the skirt is meshed with $5 \mathrm{~mm}$ elements size, the alloy jacket is meshed with $3 \mathrm{~mm}$ elements size, and the oil well wall is meshed with $25 \mathrm{~mm}$ elements size. Material properties are assigned for each part as discussed earlier in this paper. The main objectives of performing finite element simulations is to verify the sealing process and the strength of the oil well wall as the alloy jackets expands during solidification process. The sealing process can be verified by applying 4000-psi pressure on the top of the seal and monitor pressure level with time. The sealing process is certified if the seal can stand the pressure for not less than 5 minutes. The seal in the lab did not hold the pressure of 4000 psi, it started shifting, and the pressure monitor showed that the fluid pressure dropped. This was expected because there is no external support on the well's wall (concrete), which is not the case in the real field oil wells that has concrete support, this causes the inner case to balloon under the 4000-psi pressure and reduce the friction force between the seal and the well walls. The nonlinear finite element model is used to 
simulate the lab testing conditions, while tuning the coefficient of friction between the well wall and the outer surface of the seal. The coefficient of friction is tuned until the simulation results match the lab test results. Once the coefficient of friction is determined, afterward the nonlinear finite element model is used under real field environment to test the sealing status under 4000 psi gradually increasing pressure and strength of the well's wall material under expansion of the alloy jacket as it solidifies.

The nonlinear finite element simulation contains four modules. First module is implicit heat transfer analysis to simulate thermite heat conduction to the bismuth alloy jacket, and alloy jacket conduction to deep-sea environment conditions $\left(60 \mathrm{C}^{\circ}\right)$. This heat transfer module is followed by an explicit dynamic analysis to simulate melting, and shifting of the melted alloy down the outer tube under deep-sea water pressure to seal the oil well. Solidification is not modelled at this stage, as it requires the use of EXPAN user material subroutine, which is not applicable with explicit analysis. The explicit dynamic analysis is followed by implicit heat transfer analysis that models the heat conduction between the alloy jacket and the oil well's wall, and to deep-sea water environment. The temperature profile that was estimated from the second implicit heat transfer analysis is used in implicit transient stress analysis to model the expansion using EXPAN user material subroutine, then validate sealing conditions under gradually increasing 4000-psi pressure, and verify the strength of the well's wall. Heat transfer analysis was performed on two steps, as the alloy jacket is not in contact with the well's wall until it is melted under the thermite reaction. Coupled explicit thermal/stress analysis was not used due to the lack of material subroutines that available only with the implicit finite element solver. Coupled implicit thermal/stress finite element solver is not used in simulations due to the complexity of the melting, shifting process, which will be expensive to run using the implicit solver only.

The first heat transfer analysis used elements type DC3D8, which are linear implicit elements. Thermal contact is applied between all assembly elements. Thermal conductance $7.77 \mathrm{KW} /\left(\mathrm{m}^{2} \mathrm{~K}\right)$ is 
defined between steel-to-steel contacts and alloy-to-steel contact [7]. Initial temperature conditions $(60 \mathrm{Co})$ are applied everywhere in the model. Heat convection boundary condition to deep-sea water is applied on the external surface of the sealing device using surface film boundary condition. The film coefficient is defined as $70 \mathrm{~W} /\left(\mathrm{m}^{2} \mathrm{~K}\right)$. The temperature measurements from the experimental thermite reaction in the test lab are applied as temperature boundary conditions at the outer surface of the inner tube. Surface heating loading condition is applied on the outer surface of the outer tube to correct for the heat loss through heat convection to air,

$$
Q=A h_{\text {air }}\left(T_{\text {heater }}-T_{\text {air }}\right), \quad J /\left(m^{2}{ }^{o} C\right)
$$

Where $A$ is the area of the external surface of the inner tube, $\mathrm{h}_{\mathrm{air}}$ is the heat convection coefficient to air, $T_{\text {heater }}$ is the measured temperature by the thermocouples, and $T_{\text {air }}$ is the air temperature during the test $\left(21^{\circ} \mathrm{C}\right)$. Transient heat transfer analysis module is used to simulate the first phase of the heat transfer process for 2000 sec. Fig. 5 shows the temperature distribution at 3 different times along the BiSN sealing device.

The temperature results from the transient heat transfer analysis shows that the heat travels in the downwards direction, which indicate that the top part of the bismuth alloy jacket will start melting and separating first from the case. Temperature at a point on the outer surface of the bismuth alloy jacket is shown in Fig. 6. It can be noticed from the temperature profile that the temperature increases rapidly due to the thermite heat reaction, then it does not sustain itself for a long time. This is because Thermite is burning in a similar way to a candle, which is essential characteristic and one of the motives behind using it as the heat source. The objective is to partially melt and shift the bismuth alloy jacket down to the top of the skirt (Fig. 1), then starts solidifying and expanding to seal the oil well. If the heat generated lasts for longer time it may lead to the alloy jacket to melt completely and pass through the skirt, which will lead to failure of the sealing process. This is not 
an assumption but that was the conclusion after many trials at the testing lab, which led to the decision to reduce the thermite heat reaction by adding sand.

The temperature profile that was determined using heat transfer analysis is used as a predefined field in an explicit dynamic analysis. The aim of this phase of the simulation is to simulate the melting and shifting of the bismuth alloy jacket along the plug external surface to seal the gap with the oil well. The simulation time will stop as the material starts solidification. The simulation time is estimated by checking the heat transfer analysis temperature results, as the alloy jacket material temperature is around $138{ }^{\circ} \mathrm{C}$. The simulated time was estimated to be $5000 \mathrm{sec}$. C3D8R elements were used in the simulation with combined stiffness and viscous hourglass control. Similar to the heat transfer analysis, contact surfaces are defined everywhere in the model. Penalty friction formulation is used where friction coefficient of 0.78 [8] is defined for steel to steel contacts, while friction coefficient of the bismuth alloy jacket to steel is around 0.35:0.0 as the temperature increases at the interface to exceed $138{ }^{\circ} \mathrm{C}$ (melting temperature of the bismuth alloy). Tuning of the friction coefficient between bismuth and steel to match experimental results is not performed in this step analysis. As shifting of the alloy jacket is mainly controlled by the melting temperature $\left(138{ }^{\circ} \mathrm{C}\right)$ and not the friction coefficient. The friction coefficient is the main parameter, once the material starts solidifying and the 4000 psi is applied to check sealing integrity. User material $D L O A D$ is used to model air pressure $(101 \mathrm{kPa})$ distribution along the alloy Jacket. The aim of this user subroutine is to cancel the loading pressure once the alloy jacket is in contact with the oil well inner surface. Gravity load $\left(9.8 \mathrm{~m}^{2} / \mathrm{s}\right)$ is applied to model the gravitational effect as the alloy jacket shifts along the external surface of the sealing device. Simulation results are shown in Fig. 7.

The bismuth alloy jacket melts and shifts along the plug as shown in Fig.7-b, the melted alloy did not pass through the skirt, which is very essential for the sealing to be efficient. Obviously, the results here are shown for the 4.5 case plug, the finite element simulation tool can be used to run 
simulations on different plug sizes to check their design parameters. The melting and shifting phase is modelled using the explicit dynamic FE, as there is bug in Abaqus 6.11. Field Variables are not supported by Abaqus/Cae and using them by editing the input file leads to a conflict with reading the previous temperature profile from the heat transfer analysis. Field variables are needed to model the phase change of the Thermal Expansion Coefficient. Thermal expansion coefficient of the alloy jacket is affected by the phase transformation of the alloy. To overcome this issue, the final deformed shape of the alloy jacket (before solidification phase) is modelled in second heat transfer analysis followed by implicit FE analysis and user material EXPAN is used to model the cooling and phase transformation of the thermal expansion coefficient.

The test case simulates the sealing process of an oil-well of 4.5 inch case size, with no support on the external surface of the case (not similar to the real case, where the case has a concrete support on the outside). The experimental test results showed that the Bridge-Plug holds up to 4000 psi pressure before it starts shifting. The main objective of this analysis is regulating the coefficient of friction between the alloy jacket and the case till it matches the experimental test results. User material $D L O A D$ is used to model water pressure distribution along the alloy jacket. Temperature profile from the second heat transfer analysis is used in the following implicit dynamic FE analysis. User material EXPAN is used to model thermal expansion coefficient of the alloy jacket. Implicit Dynamic Transient FE analysis is performed to simulate the cooling/expansion process to calculate: the maximum Von Misses stress in the Case under a mix of water pressure and alloy-jacket expansion, and the maximum pressure difference that the Bridge-Plug can hold until it starts shifting along the case. The numerical results show that the critical coefficient of friction, which leads to the Bridge-Plug to shift at pressure difference of $4000 \mathrm{psi}$ is 0.25 . This coefficient of friction value gives confidence in the simulation results, as it matches the standard coefficient of friction between bismuth and Steel [3]. Maximum stresses in Case $=378 \mathrm{MPa}=55,000$ psi. This value is safe for the old oil wells that use Steel Grade J55. It is yet not safe for standard steel type of yield equals 
to $215 \mathrm{MPa}$ and ultimate stress equals to $450 \mathrm{MPa}$. Fig. 8 shows the stress distribution in the case (oil well's wall), and the shifting of the bridge-plug at 4000 psi pressure.

Shifting of the bridge-plug along the case as the 4000 psi pressure overcomes both the friction force and the alloy expansion force between the bridge-plug and the case and is due to the ballooning of the case under the applied fluid pressure, which reduce the contact surface between the bridgeplug and the case. To verify the sealing of the bridge-plug in a real field case, a new simulation is required by including the external concrete wall that supports the well case. Including the concrete wall will strengthen the case and will resist the ballooning of the bridge-plug, which will increase the friction force between the bridge-plug and the case. Next, the second heat transfer analysis and the implicit dynamic finite element analysis are repeated after including the concrete wall support.

Concrete jacket is modelled with, Radius $=2.5^{*}$ Case_outer_radius, as shown in Fig. 9(a). Fig. 9(b) shows the temperature distribution at the end of heat transfer analysis simulation time, which is longer than the simulation time of the test case by $400 \mathrm{sec}$. Longer simulation time is used as the low concrete conductivity leads to longer cooling time for the Bridge-Plug average temperature reaches the water temperature $\left(60^{\circ} \mathrm{C}\right)$. The concrete-jacket adds support to the Case and does not allow it to balloon under internal water pressure and alloy jacket expansion during solidification process. Thus, it allows for full contact between alloy jacket and Case, which assist in handling the pressure difference higher than 4000 psi longer than 5 minutes, with maximum stresses in the Case of $(252 \mathrm{MPa}=36549 \mathrm{psi})$. Estimation of the critical pressure difference that leads to Bridge-Plug to shift can be done either numerically by gradually increasing pressure till it moves, or analytically using MathCad (Appendix A), and the Contact Pressure between alloy jacket and Case as it solidifies. The current contact length between alloy jacket and Case is $280 \mathrm{~mm}$. 


\section{Conclusion}

One of the major problems in oil industry is well abandonment either temporary or permanently. The well has to be sealed to prevent any gas or oil leakage that may cause environmental issues. The present sealing technology is expensive and cannot resolve the issue in hand permanently. A new patent technology, which is called "the bridge-plug", has promising features that may help to

resolve the sealing problem of abandonment wells. The technology is based on using low melting temperature bismuth alloy as a sealing material and thermite reaction as a heat source. By inserting the bridge-plug inside the well's inlet and ignite the thermite reaction, enough heat is generated to melt the bismuth alloy, which then shifts along the bridge-plug. Once the bismuth alloy shifts, it is necessary to stop shifting before the bridge-plug end, then starts cooling and solidification processes. The advantage of using the bismuth alloy is its expansion property while it is solidifying. The bismuth alloy expands as it solidifies, which increases the friction forces between the bridgeplug and the inner surface of the case (oil well). Thus increases its resistance to pressure difference that is built up with time inside the well. The thermite mix and the inner tube design of the bridgeplug has to be optimized to avoid producing heat, that may cause the bismuth alloy to melt completely and pass through the bridge-plug end.

Nonlinear finite element analysis is used to simulate the sealing process and verify its efficiency. The sealing efficiency is validated by testing its performance under pressure difference of 4000-psi up to 5 minutes in test lab conditions. The bridge-plug was tested experimentally in the test lab and the temperature due to thermite heat reaction was measured and recorded. The bridge-plug seal failed to take the 4000-psi pressure difference and it started shifting immediately. The thermal and mechanical results of the plug under test lab conditions were used to assist in parameter identification of the finite element analysis of the plug under real field conditions. The temperature measurements were used after correcting them to include convection heat loss to air, to simulate the heat transfer process using finite element heat transfer analysis. The heat transfer analysis is 
followed by an explicit dynamic analysis that simulates the melting and shifting of the bismuth alloy jacket. Then, a sequential heat transfer analysis followed by an implicit dynamic analysis is used to model the solidification and expansion process using EXPAN user_material subroutine. The simulation tool is used to simulate the experimental results of the bridge-plug under the test lab conditions, and then estimate the coefficient of friction between the bridge-plug and the case. Once the simulation tool is adjusted using the test lab conditions, it is then used under real field conditions (temperature, pressure, concrete support to case) to verify the sealing process and its efficiency. The simulation results of the real test case verify the efficiency of the sealing process and the strength of the oil well case to stand both the water pressure and expansion forces of the bismuth alloy jacket. The simulation tool can be used to verify different sizes of bridge-plug and also to design optimize its geometrical and chemical parameters. The bridge-plug once installed to seal the oil well; it can be removed later by melting the bismuth alloy completely away. One of the expected issues with the bridge-plug is the creep characteristics of the bismuth alloy material. This

issue can be investigated to determine different alloy mix to reduce the effect of creep. Thus, a set of accelerated creep tests are required to verify the new alloy design. The discussed new technique can be used in sealing, resealing, and seal-removal of oil wells under water and it is cheap and resolves many of the short comes of using other universal plugs (cost, sealing quality). It even provides solution to oil-well walls corrosion as the melted bismuth alloy will fill the corroded areas before solidifying and expanding to seal the oil-well.

\section{References}

1. B. Liptal, K. Venczel, "Instrument and Automation Engineers' Handbook: Process Measurement and Analysis", $5^{\text {th }}$ edition, 2014 CRC Press publisher.

2. Working Document of the NPC North American Resource Development Study, "Plugging and Abandonment of Oil and Gas Wells", 2011. 
3. K. Ohguchi, K. Sasaki, M. Ishibashi, and T. Hoshino, "Plasticity-Creep Seperation Method for Viscoplastic Deformation of Lead-Free Solders", JSME International journal, Series A, Vol. 47, No.3, 2004, pp. 371-379.

4. R. Fan, H. Lu, K. Sun, W. Wang, and X. Yi, "Kinetics of Thermite Reaction in Al-Fe2O3 System", Journal of Thermochimica Acta, Vol. 440, Issue 2, 2006, pp. 129-131.

5. M. Starink, "The determination of activation energy from linear heating rate experiments: a comparison of the accuracy of isoconversion methods", Journal of Thermochimica Acta, Vol. 404, Issue 1-2, 2003, pp. 163-176.

6. T. Ozawa, "Estimation of Activation Energy by Isoconversion Methods", Journal of Thermochimica Acta, Vol. 203, Issue C, 1992, pp. 159-165.

7. H. Yunsu, "Thermal contact conductance of nominaly flat surfaces. Springer J HeatMass Transfer , Vol. 43, Issue 1, 2006, pp. 1-5.

8. http://www.engineershandbook.com/Tables/frictioncoefficients.htm.

\section{Appendix A}

\subsection{MathCad file to verify sealing resistance}

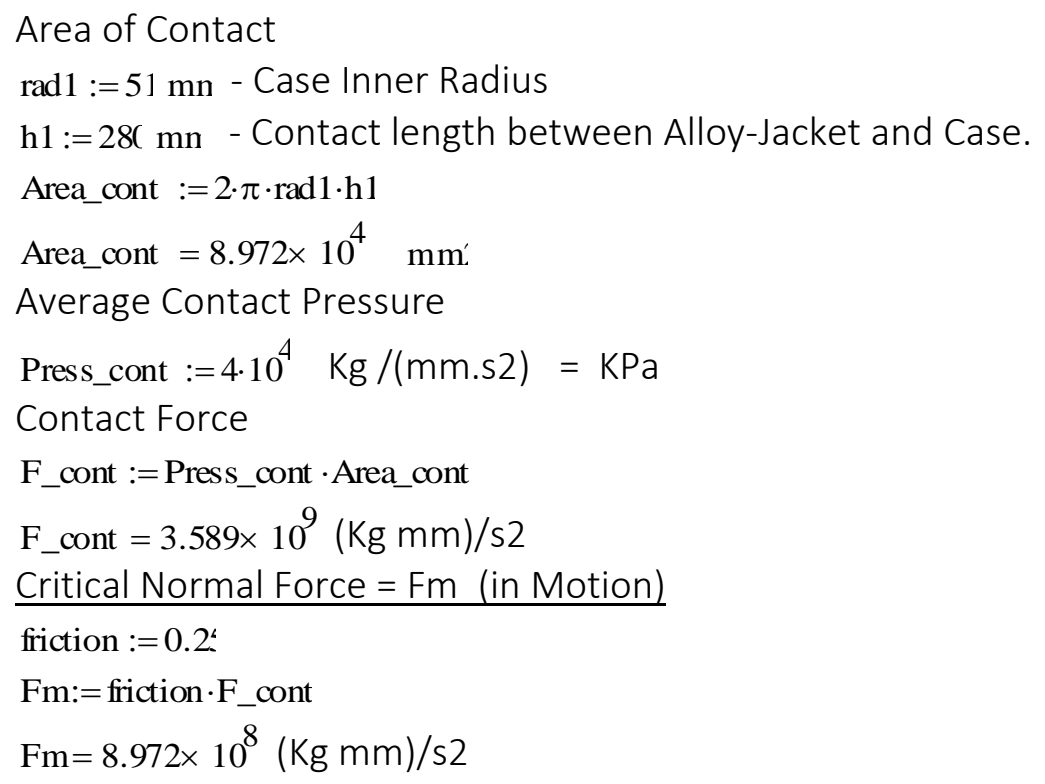


Area of Pressure

$\operatorname{rad} 2:=51 \mathrm{mn}$

Area_press $:=\pi \cdot(\operatorname{rad} 2)^{2}$

Area_press $=8.171 \times 10^{3} \mathrm{~mm}^{\prime}$

Pressure Difference in Oil Well

Press_well $:=2757 ! \mathrm{Kg} /(\mathrm{mm} . \mathrm{s} 2)=\mathrm{KPa}$

Pressure Force

Force_Press :=Press_well-Area_press

Force_Press $=2.254 \times 10^{8}(\mathrm{Kg} \mathrm{mm}) / \mathrm{s} 2$

So it can be concluded that Force_Press is less than $F_{m}$, so it will hold the pressure. Next evaluate at what pressure difference will it shift:

It will shift when the Pressure Force reaches $\left(F_{m}\right)$

Critical Pressure

Press_critical $:=\frac{\text { Fm }}{\text { Area_press }}$

Press_critical $=1.098 \times 10^{5} \mathrm{Kg} /(\mathrm{mm} . \mathrm{s} 2)=\mathrm{KPa}$

Press_critical_psi $:=\frac{\text { Press_critical }}{6.894}$

Press_critical_psi $=1.593 \times 10^{4} \mathrm{psi}$

\subsection{Subroutine DLOAD for pressure load application}

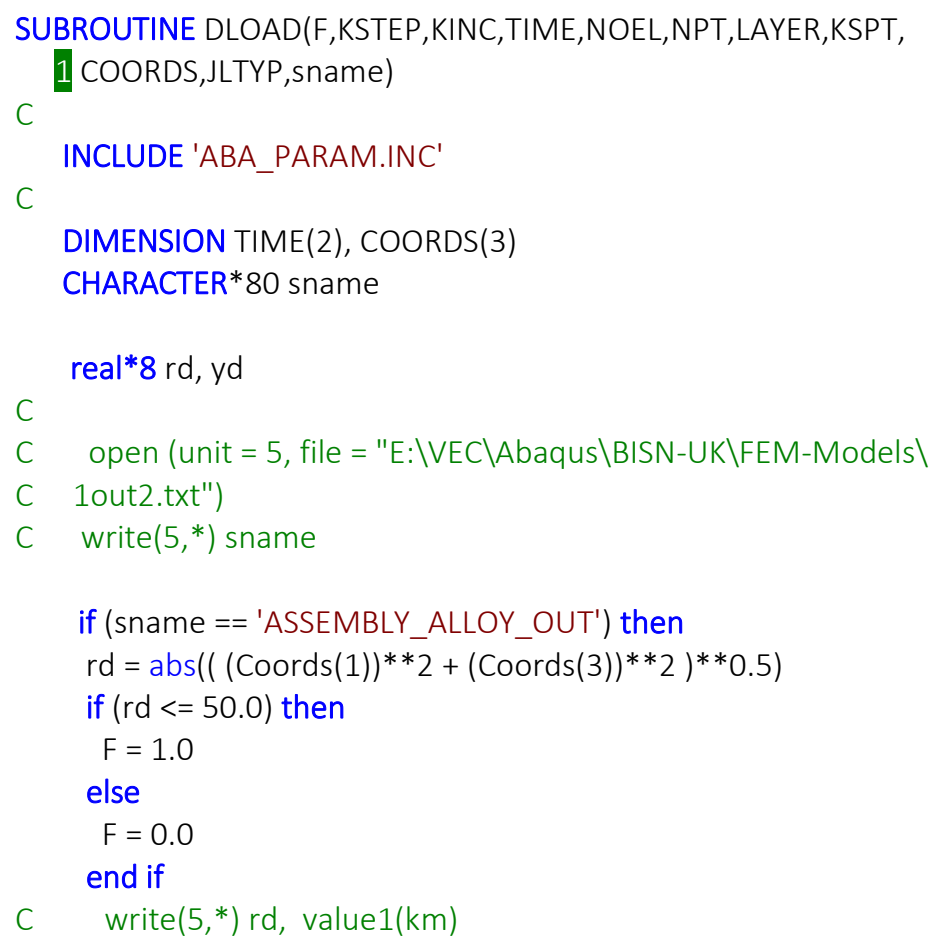




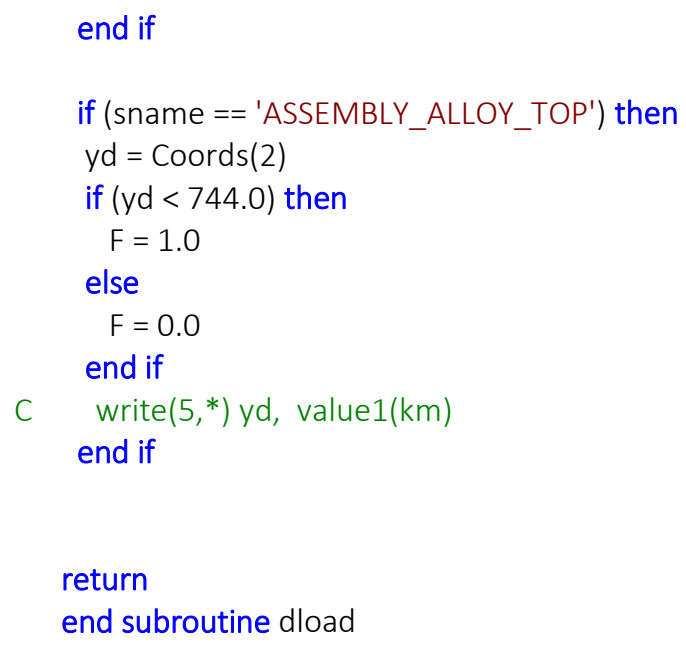

\subsection{Subroutine UEXPAN}

SUBROUTINE UEXPAN(EXPAN,DEXPANDT,TEMP,TIME,DTIME,PREDEF, C 
RETURN

END

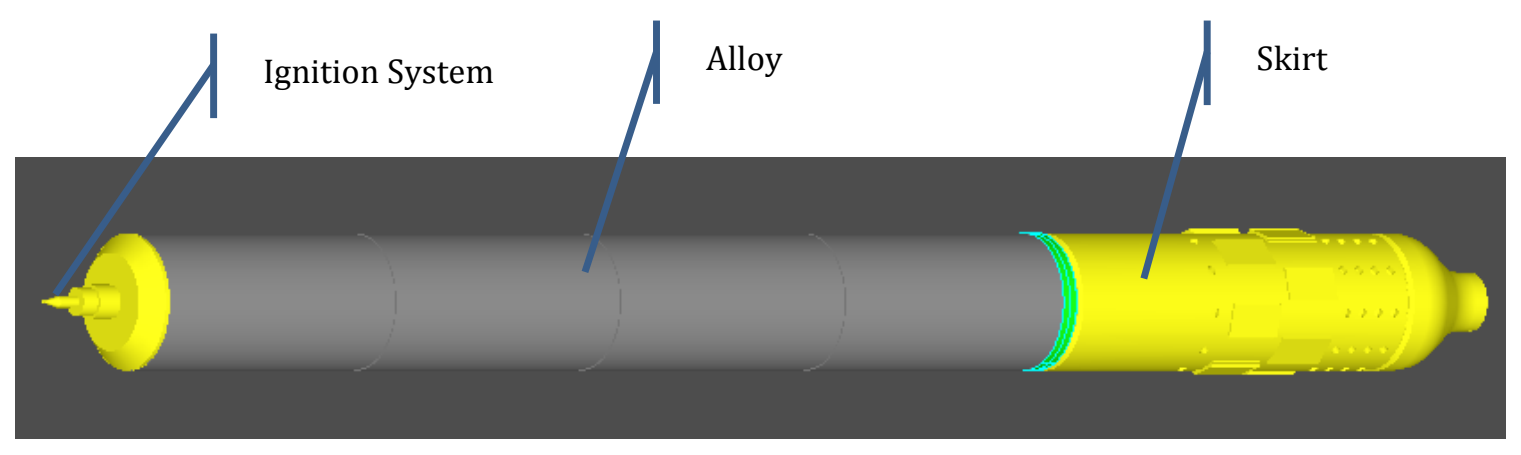

Thermite

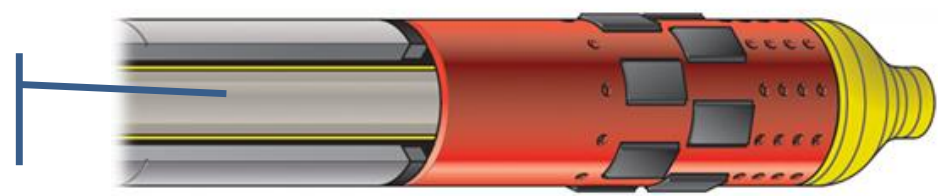

Figure 1: BiSN new bridge plug technology.

Table 1: Material thermal properties

\begin{tabular}{|l|l|l|l|l|}
\hline Material property & $\begin{array}{l}\text { Thermal } \\
\text { Conductivity } \\
(\mathrm{W} / \mathrm{m} . \mathrm{K})\end{array}$ & Density $\left(\mathrm{Kg} / \mathrm{m}^{3}\right)$ & $\begin{array}{l}\text { Specific heat } \\
\text { (J/Kg.K })\end{array}$ & $\begin{array}{l}\text { Phase } \\
\text { transformation } \\
\text { heat }(\mathrm{KJ} / \mathrm{Kg})\end{array}$ \\
\hline Sn-57Bi-1Ag & 155.0 & 8720 & 188.28 & 46.5224 \\
\hline SA-335 & $39.5 @ 21^{\circ} \mathrm{C}$ & 7830 & $442 @ 21^{\circ} \mathrm{C}$ & - \\
& $25.9 @ 760^{\circ} \mathrm{C}$ & & $969 @ 760^{\circ} \mathrm{C}$ & \\
\hline
\end{tabular}




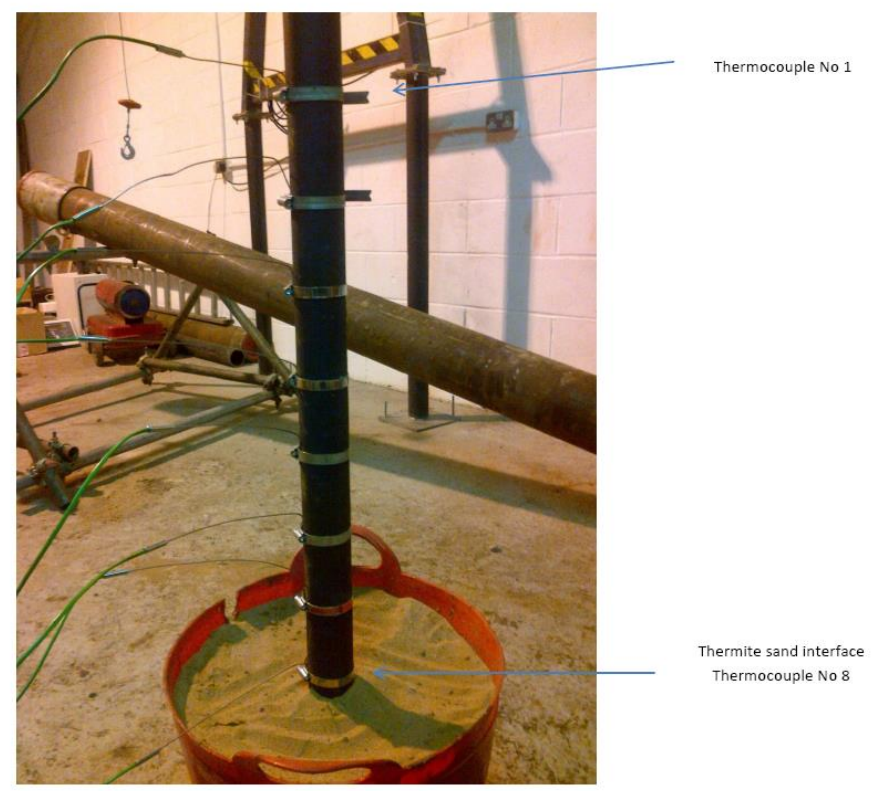

Figure 2: Experimental setup of thermite heat reaction measurements.

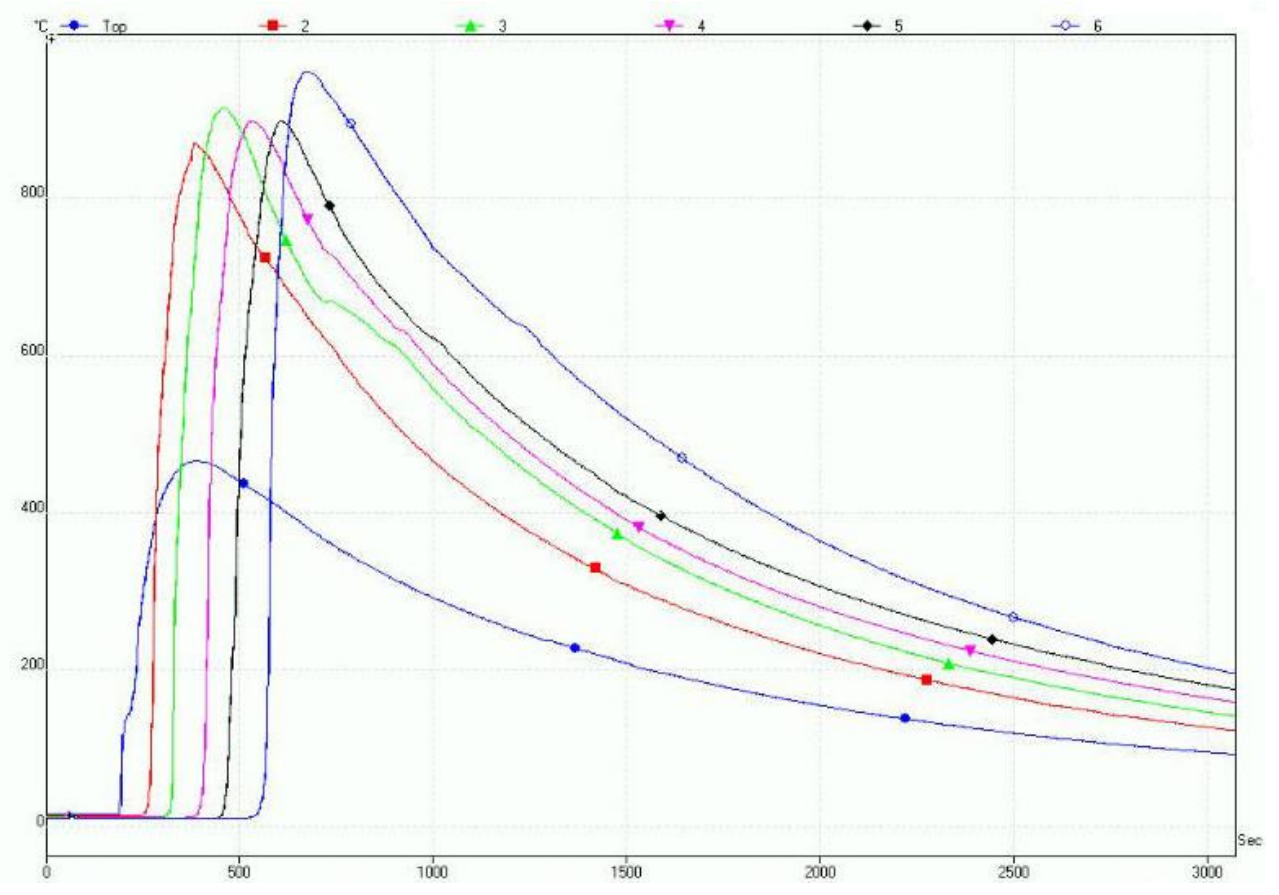

Figure 3: Temperature recording by data acquisition system. 


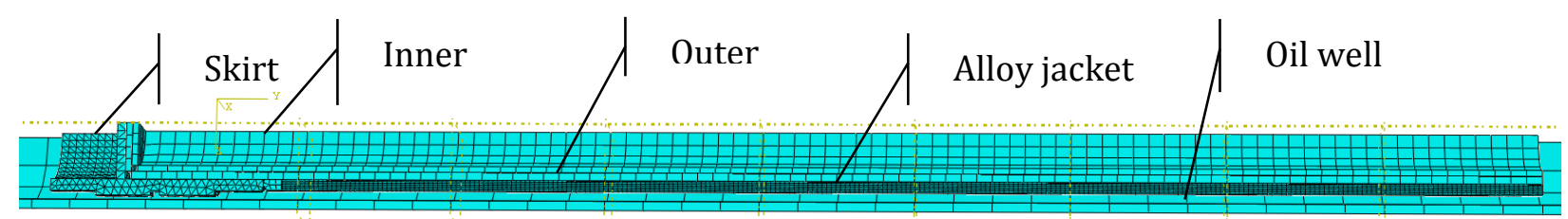

Figure 4: Meshed finite element model of the sealing device

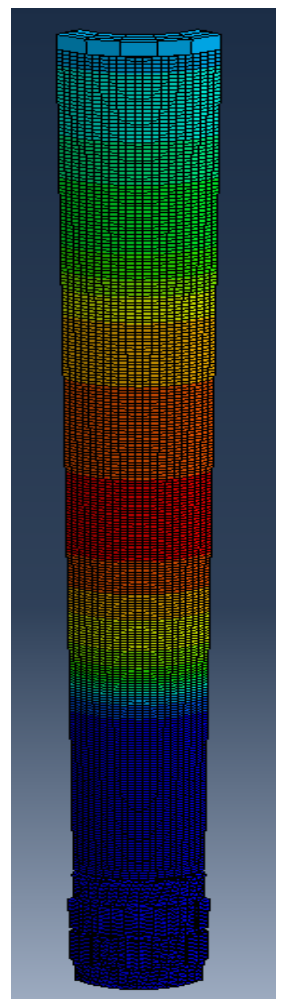

Time $=547$ sec

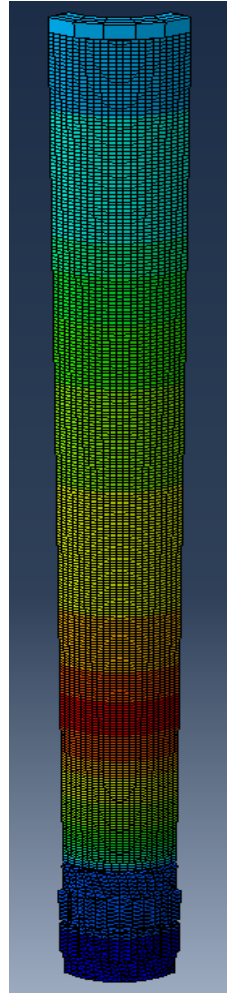

Time $=1500$ sec

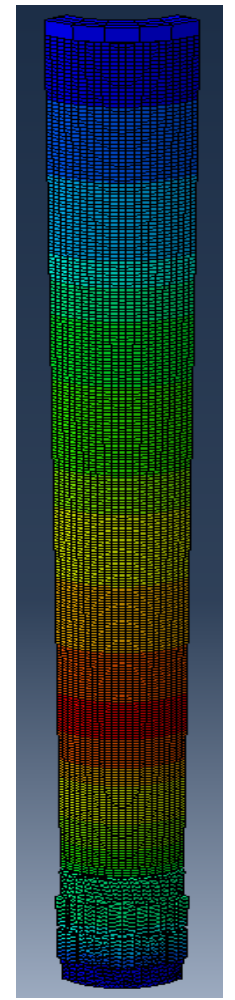

Time $=4000 \mathrm{sec}$

Figure 5: Temperature distribution along the sealing device. 


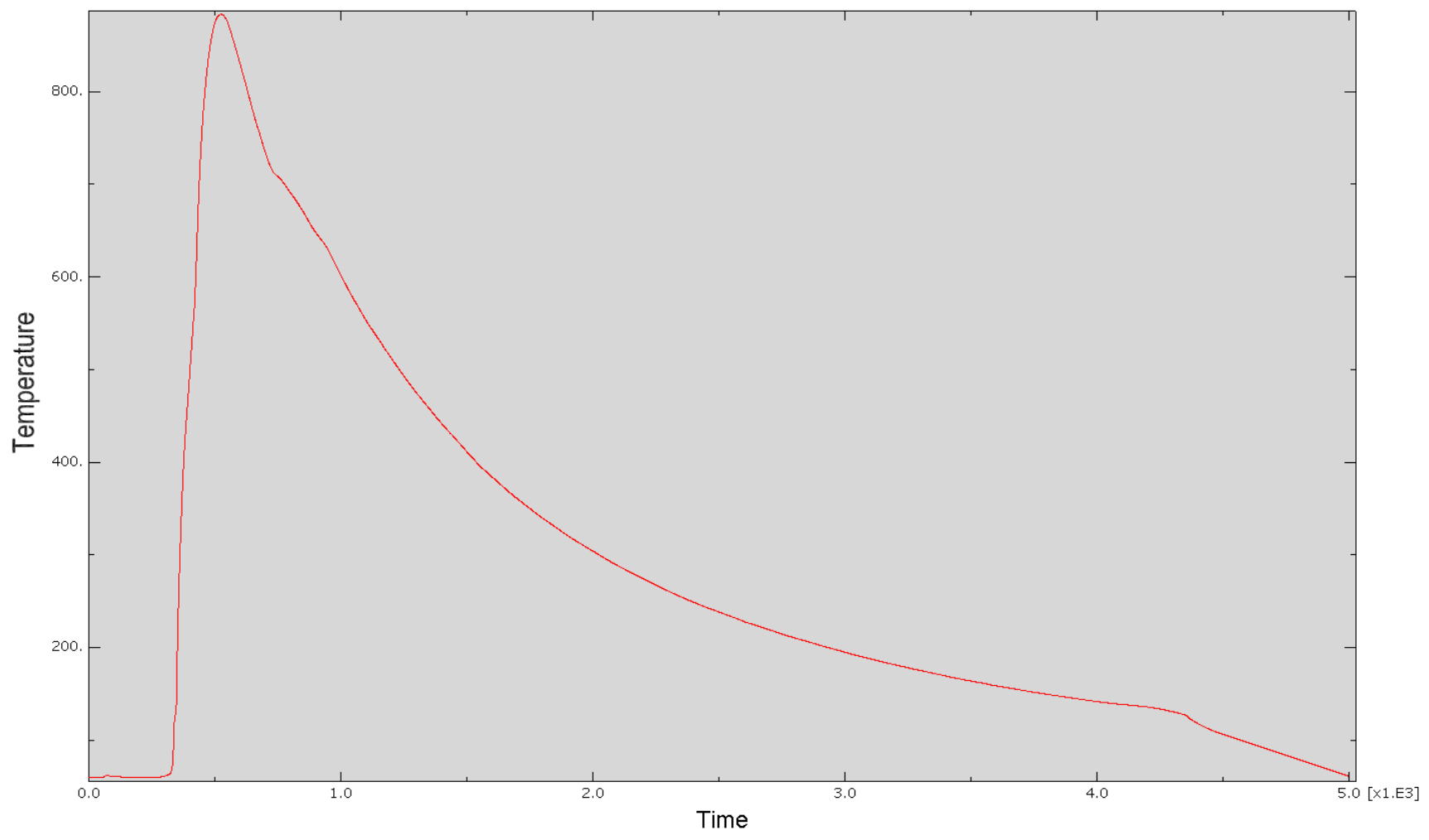

Figure 6: Heat Transfer Analysis Temperature Profile on alloy jacket. 


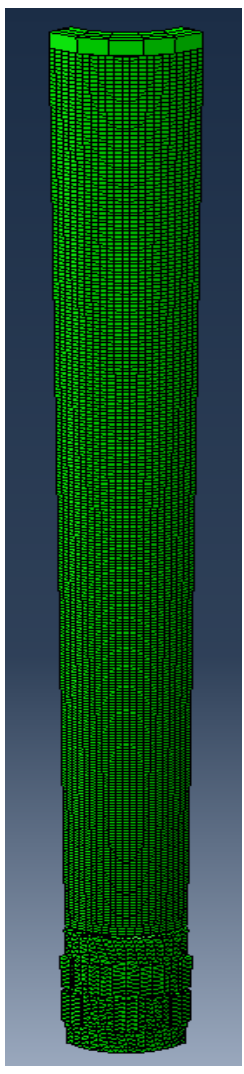

(a)

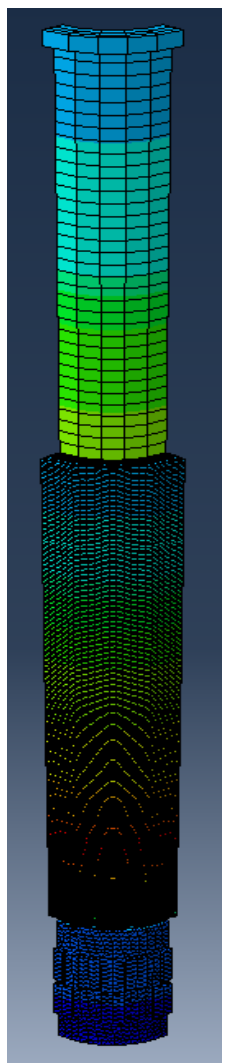

(b)

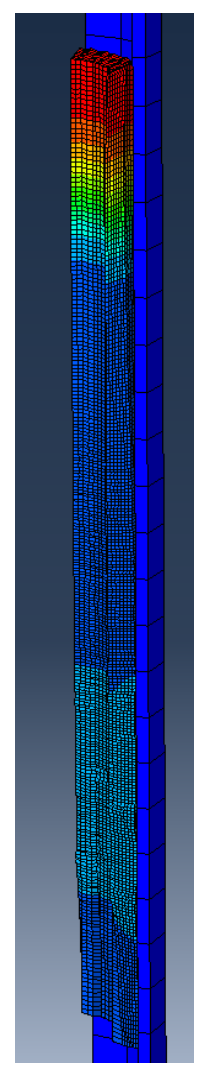

(c)

Figure 7: Deformed alloy jacket as it Melts and Shifts along the Plug. 

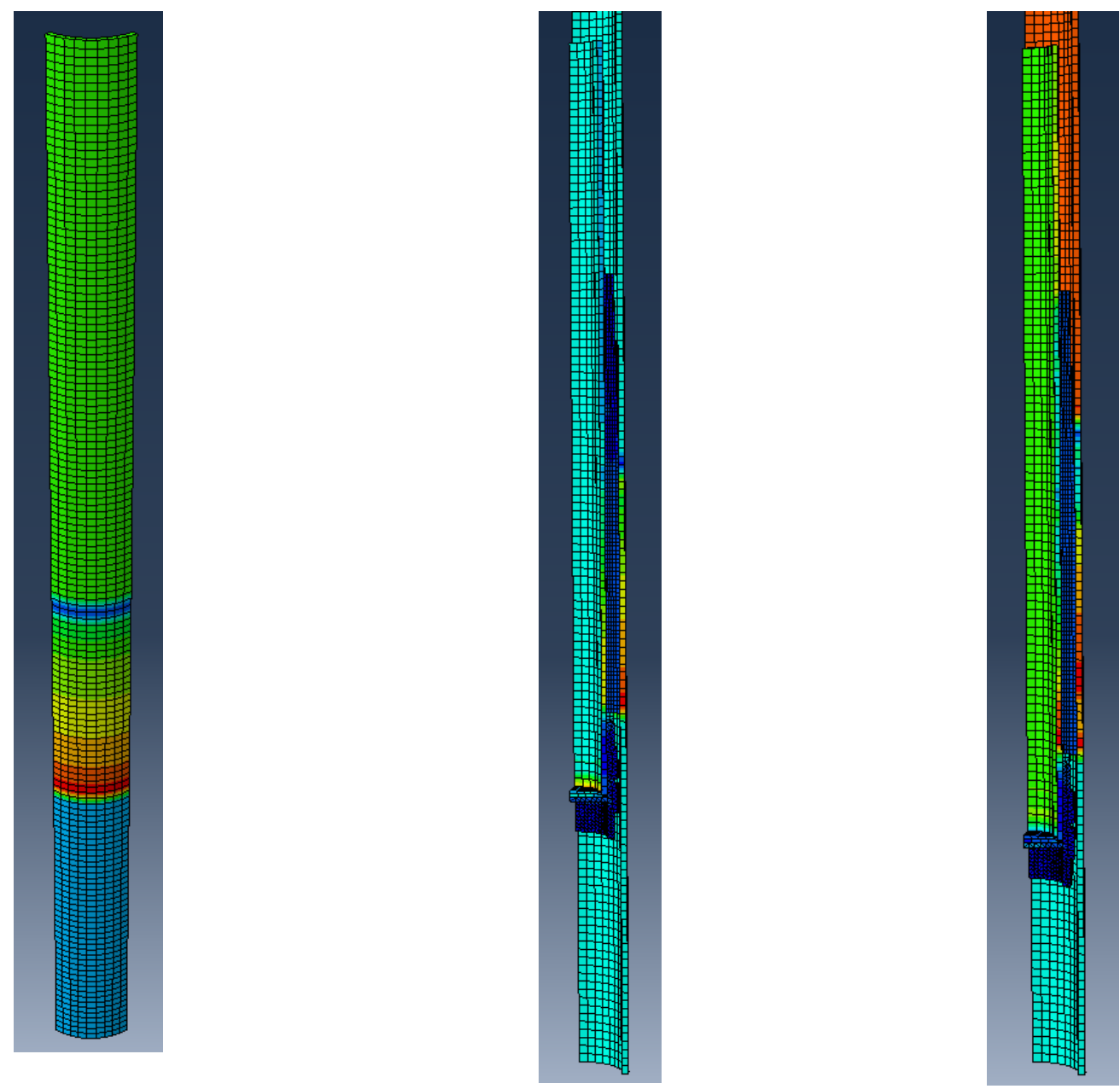

Figure 8: Stresses in Case and Bridge-Plug Moving at pressure difference 4000 psi 


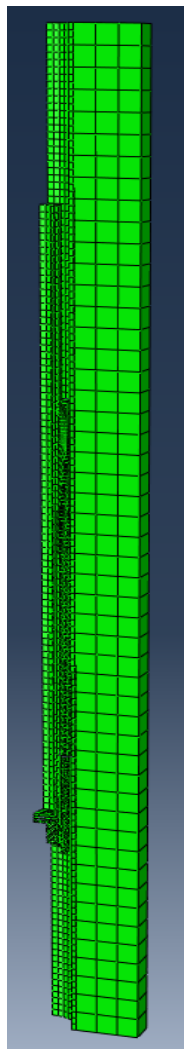

(a) - Concrete Jacket Setup

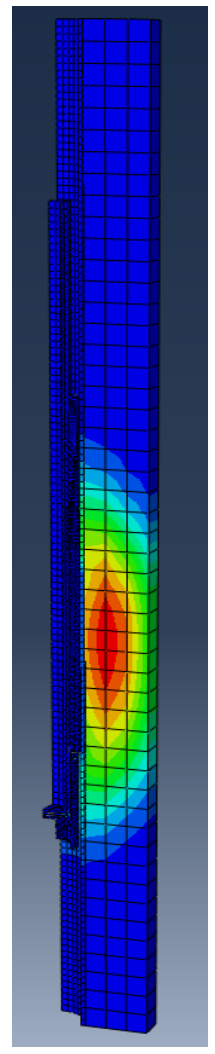

(b) - Temperature Distribution

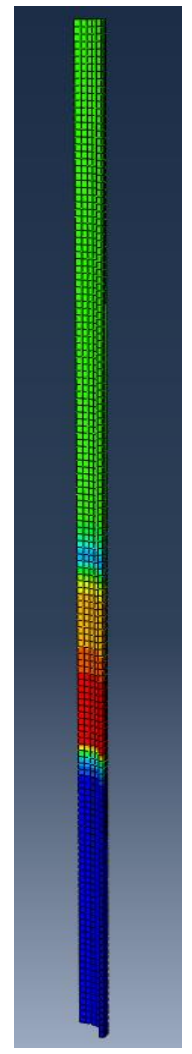

(c) - Max stresses in Case

Figure 9: Simulation results of real-case sealing. 